\title{
Short-term effects of delivery methods on postpartum pelvic floor function in primiparas: a retrospective study
}

\author{
Xinxin Zhang ${ }^{1}$, Xiangjian Zhang ${ }^{2}$, Yaoyao Wang ${ }^{1}$, Xianping Huang ${ }^{3}$, Xiangyu Chen $^{1}$, Ledan Wang ${ }^{1}$ \\ ${ }^{1}$ Department of Gynecology, The Second Affiliated Hospital and Yuying Children's Hospital of Wenzhou Medical University, Wenzhou, China; \\ ${ }^{2}$ Wenzhou Central Hospital, Wenzhou, China; ${ }^{3}$ Department of Obstetrics, The Second Affiliated Hospital and Yuying Children's Hospital of \\ Wenzhou Medical University, Wenzhou, China \\ Contributions: (I) Conception and design: X Zhang, L Wang; (II) Administrative support: X Zhang, Y Wang; (III) Provision of study materials or \\ patients: X Zhang, X Huang; (IV) Collection and assembly of data: All authors; (V) Data analysis and interpretation: X Zhang and L Wang; (VI) \\ Manuscript writing: All authors; (VII) Final approval of manuscript: All authors. \\ Correspondence to: Ledan Wang. Department of Gynecology, The Second Affiliated Hospital and Yuying Children's Hospital of Wenzhou Medical \\ University, Wenzhou 325027, China. Email: ledanwang2020@163.com.
}

\begin{abstract}
Background: The present study sought to investigate the short-term effects of different delivery methods on postpartum pelvic floor function in Chinese primiparas.

Methods: Primiparous women who delivered a full-term, cephalic, singleton infant at our hospital between January 1, 2018 and August 15, 2019 were recruited into this study. All women underwent pelvic floor function screening at 6-8 weeks postpartum. Tests included postpartum Pelvic Organ Prolapse Quantification (POP-Q) score, incidence of urinary incontinence, pelvic floor muscle (PFM) strength, and Pelvic Floor Distress Inventory Questionnaire-Short Form 20 (PFDI-20) score.
\end{abstract}

Results: A total of 284 postpartum women were recruited into the study. Of the participants, 147 had undergone vaginal delivery, 37 had undergone intrapartum cesarean delivery (ICD), and 100 had undergone elective cesarean delivery (ECD). Points $\mathrm{Aa}, \mathrm{Ba}, \mathrm{Ap}$, and $\mathrm{Bp}$ showed a greater degree of prolapse in the vaginal delivery group than in the ECD group $(\mathrm{P} \leq 0.05)$. UI was less prevalent in ECD group relative to the vaginal delivery group $(\mathrm{P} \leq 0.05)$. Tonic $\mathrm{PFM}$ contraction was weaker in the vaginal delivery group than in the ECD and ICD groups $(\mathrm{P} \leq 0.05)$. Significant differences were also observed between the vaginal delivery group and the ECD group with respect to PFDI-20 scores $(\mathrm{P} \leq 0.05)$.

Conclusions: Compared with vaginal delivery, ECD was strongly linked to a lower risk of pelvic organ prolapse (POP) and UI, stronger tonic PFM strength, and lower PFDI-20 scores. ECD confers relatively better protection against pelvic floor dysfunction (PFD) than does ICD.

Keywords: Primipara; vaginal delivery; intrapartum cesarean delivery (ICD); elective cesarean delivery (ECD); pelvic floor function; POP

Submitted Feb 04, 2021. Accepted for publication Mar 24, 2021.

doi: 10.21037/apm-21-485

View this article at: http://dx.doi.org/10.21037/apm-21-485

\section{Introduction}

Pelvic floor dysfunction (PFD) comprises a variety of clinical conditions which affect the pelvic floor. These conditions can lead to sexual dysfunction, pelvic organ prolapse (POP), issues with voiding and defecation, bladder and bowel incontinence, and pelvic pain (1). In a study conducted in the United States, Nygaard et al. (2) found that $24 \%$ of women suffered PFD. Based on a U.S. claims and encounters databases, the lifelong risk of surgery for stress urinary incontinence (SUI) or POP in women is estimated to be $20 \%$ (3). Among women in China, PFD is fairly common and has begun to attract more attention, with an increasing amount of resources directed to the study of this condition. 
Epidemiological studies have suggested that PFDs are associated with childbirth, since their occurrence is correlated with parity (4). During pregnancy, delivery, and the puerperium, women experience hormonal and physical changes, and the resulting stress on the pelvic floor can cause PFD $(5,6)$. However, in a recent study, the authors concluded that the mode of delivery is not correlated with variations in the short-term development of postpartum PFD (7). So far, the effects of delivery mode on pelvic floor function have remained controversial.

Here, we set out to investigate the short-term effects of various modes of child delivery on postpartum pelvic floor function in Chinese primiparas with full-term singleton births. We present the following article in accordance with the STROBE reporting checklist (available at http://dx.doi. org/10.21037/apm-21-485).

\section{Methods}

\section{Research subjects}

All procedures performed in this study involving human participants were in accordance with the Declaration of Helsinki (as revised in 2013). Ethical approval for this study was granted by the institutional review board of the Second Affiliated Hospital of Wenzhou Medical University (Zhejiang, China), (No. LCKY2019-287). Written informed consent was obtained from all participants. Women who had delivered at the Obstetrics Department of the Second Affiliated Hospital of Wenzhou Medical University between January 1, 2018 and August 15, 2019 were retrospectively enrolled. All participants were Chinese primiparas aged $\geq 18$ years old, who had experienced only singleton cephalic pregnancies and had undergone vaginal delivery, elective cesarean delivery (ECD), or intrapartum cesarean delivery (ICD) 6 to 8 weeks previously. All of the women had clean lochia. Participants with a history of lower urinary tract malformation or pelvic surgery were excluded, as were those who had received pelvic floor muscle (PFM) training in the previous 12 months, or who had medical complications or reproductive tract malformations.

\section{Data collection}

Participants' maternal and obstetrical features, including mode of delivery, weight gain during pregnancy, prepregnancy body mass index (BMI), delivery weight, and occupation, from their medical records were reviewed.
Assessments of pelvic floor function among the participants were conducted by trained specialists who were blinded to the group allocation. The Pelvic Organ Prolapse Quantification (POP-Q) approach was used to measure the positions of vaginal structures relative to the hymenal ring. Cases of SUI, which usually occurs with coughing, laughing, sneezing, running, or jumping, were assessed through discussion with each participant. The women were also asked about urgent urinary incontinence (UUI), which causes urine leakage and a strong urge to void, as well as if they had experienced mixed urinary incontinence (MUI), which manifests with symptoms of both SUI and UUI.

An experienced team of clinicians examined the strength of the PFMs of each participant using digital palpation. Before the physical examination, each participant emptied the bladder and positioned themselves in the lithotomy position. In each case, the participant was asked to squeeze the PFMs while avoiding any visible contraction of the abdominal muscles, glutei, or hip, or any pelvic movement (8). For measurement of rapid PFM contraction, participants were instructed to contract the PFMs as forcefully as possible. To determine tonic PFM contraction, each participant was instructed to maintain the contraction for as long they could. For the assessment of digital palpation (9), the middle and index fingers were inserted $2-3 \mathrm{~cm}$ deep into the vaginal canal to locate the levator ani muscle. Next, the 2 fingers were separated so that they were touching the 2 sides of levator ani muscle. Meanwhile, the clinician placed their other hand on the abdomen to ensure the abdominal muscles were relaxed. To assess the scale of the strength of the PFM, the Modified Oxford scale was employed. PFM strength was classified into $0-5$ grades and 6 classes on the basis of retraction capacity and contraction strength. The grade 0 means Nil. The grade 1 means Flicker. The grade 2 means Weak. The grade 3 means Moderate, slight lift of the examiner's fingers, no resistance. The grade 4 means Good, sufficient to elevate the examiner's fingers against light resistance. The grade 5 means Strong, sufficient to elevate the examiner's fingers' against strong resistance (10)

Participants were interviewed about any pelvic floor symptoms that had occurred after childbirth using the Pelvic Floor Distress Inventory Questionnaire-Short Form 20 (PFDI-20). The items of the questionnaire were classified based on the scores of the components evaluating urinary distress (UDI-6), colorectal and anal distress (CRADI-8) and pelvic organ prolapse distress (POPDI-6).

The present study is part of a project aimed at evaluating several issues associated with the pelvic floor. A specific a 


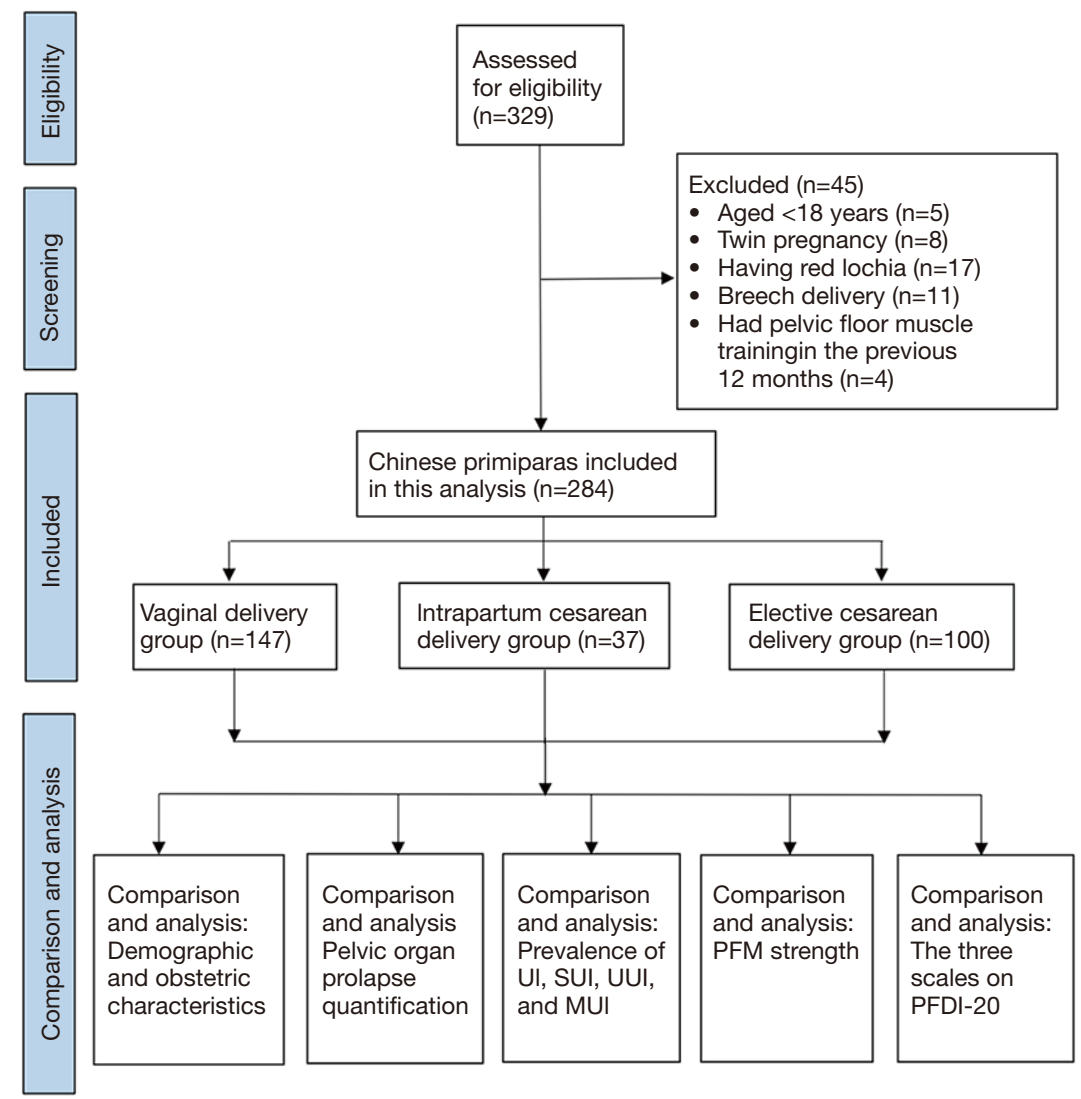

Figure 1 Detailed study selection process and the content of comparison and analysis. UI, urinary incontinenc; SUI, stress urinary incontinenc; UUI, urgent urinary incontinence; MUI, mixed urinary incontinence; PFM, pelvic floor muscle; PFDI-20, Pelvic Floor Distress Inventory Questionnaire-Short Form 20.

priori power calculation for questions on postpartum pelvic floor in primiparas does not exist.

\section{Statistical analysis}

All data were analyzed using SPSS (IBM). Continuous variables were expressed as interquartile ranges (IQR), medians, or means \pm standard deviations (SDs). Categorical variables were analyzed with the chi-square test and displayed as relative frequencies and absolute numbers. The KruskalWallis $\mathrm{H}$ test was used to assess non-Gaussian distribution variables among $\mathrm{K}$ independent samples. The Nemenyi test was conducted for further evaluation of pairwise samples. $\mathrm{P} \leq 0.05$ was considered to be statistically significant.

\section{Results}

A total of 329 women were evaluated for eligibility, of whom 45 (13.7\%) cases were excluded according to the preestablished criteria (Figure 1). Table 1 presents the women's obstetric and demographic features. Finally, 284 eligible postpartum women were recruited into the study. Of the study participants, 147 had undergone vaginal delivery, 37 had undergone ICD, and 100 had undergone ECD. Weight gain during pregnancy, pre-pregnancy BMI, age, delivery weight and occupation were comparable between the 3 groups $(P \geq 0.05)$. Among the participants who had a vaginal delivery, there were 17 (11.6\%) cases of episiotomy and 119 cases $(80.9 \%)$ of perineal laceration. Among the 17 participants who received an episiotomy, 1 underwent forceps-assisted surgery. Of the 119 cases of perineal laceration, $2^{\text {nd }}$ degree and $1^{\text {st }}$ degree natural lacerations accounted for 66 (44.9\%) and $53(36.0 \%)$ cases, respectively.

The POP-Q analysis results for the 3 groups are shown in Table 2. Relative to ICD and ECD, vaginal delivery was markedly linked to prolapse at points $\mathrm{Aa}$ and $\mathrm{Ba}$ 
Table 1 Demographic and obstetric characteristics

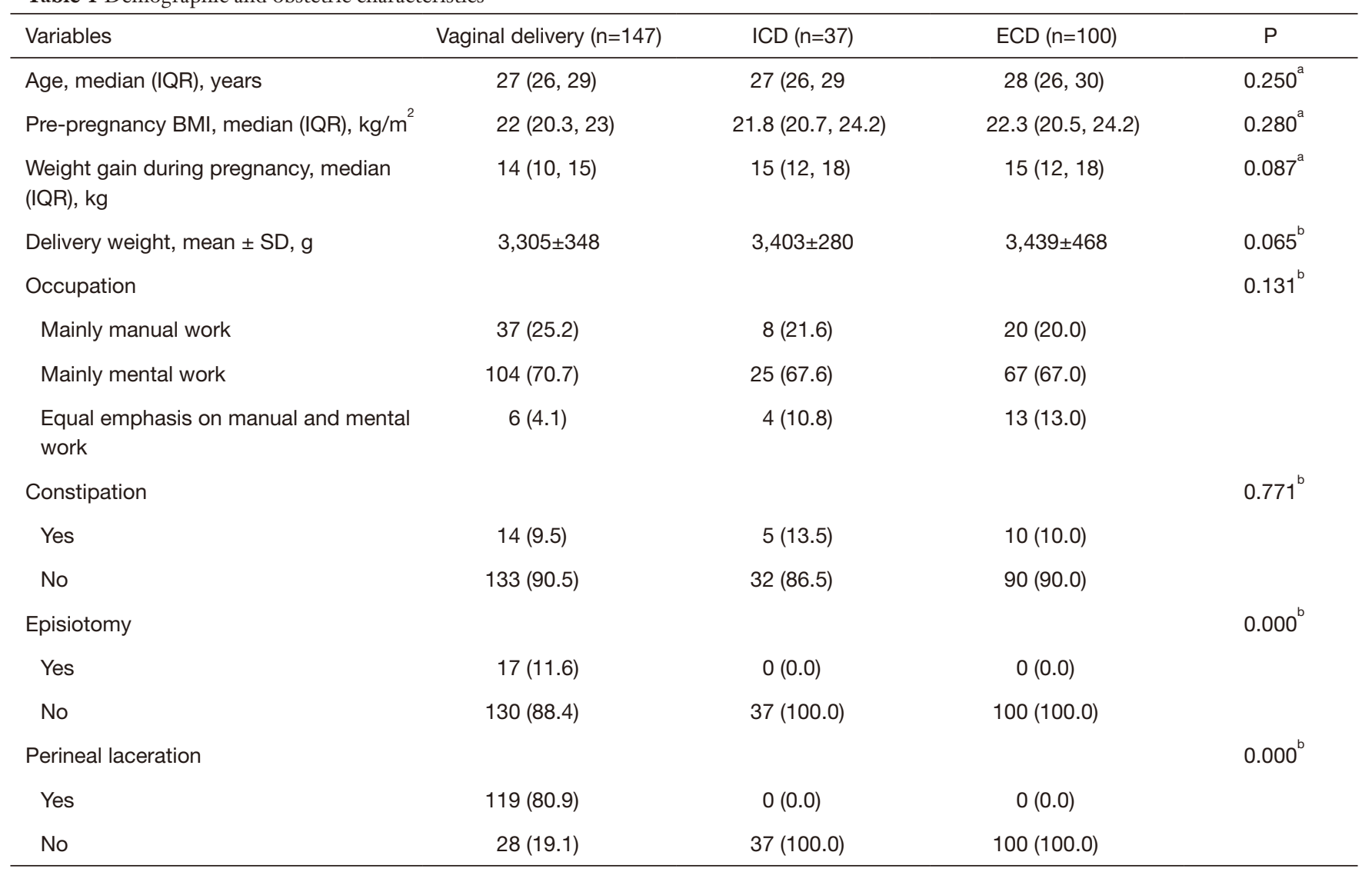

${ }^{\mathrm{a}}$, Kruskal-Wallis test; ${ }^{\mathrm{b}}, \chi^{2}$ test. ICD, intrapartum cesarean delivery; ECD, elective cesarean delivery; IQR, interquartile ranges. BMI, body mass index.

Table 2 Pelvic organ prolapse quantification; continuous variables (M, IQR)

\begin{tabular}{|c|c|c|c|c|}
\hline Variables & Vaginal delivery $(n=147)$ & $\operatorname{ICD}(n=37)$ & $\operatorname{ECD}(n=100)$ & $\mathrm{P}^{\mathrm{a}}$ \\
\hline POP-Q Ba, cm & $-1.2(-1.5,-0.8)$ & $-1.5(-1.7,-1.2)^{\star}$ & $-1.5(-1.9,-1.2)^{\star}$ & 0.000 \\
\hline POP-Q C, cm & $-4.5(-5,-4)$ & $-4.5(-5,-4)$ & $-4.5(-5,-4)$ & 0.876 \\
\hline POP-Q gh, cm & $4(3.5,4.5)$ & $3(3,3.5)^{*}$ & $3(3,3.5)^{*}$ & 0.000 \\
\hline POP-Q TVL, cm & $7.5(7,8)$ & $7.3(7,7.7)$ & $7.5(7,8)$ & 0.917 \\
\hline POP-Q Ap, cm & $-2(-2.5,-2)$ & $-2.4(-2.5,-2)$ & $-2.5(-2.7,-2)^{\star}$ & 0.007 \\
\hline POP-Q Bp, cm & $-2(-2.5,-2)$ & $-2.4(-2.5,-2)$ & $-2.5(-2.7,-2)^{*}$ & 0.007 \\
\hline POP-Q D, cm & $-6(-6.5,-5.2)$ & $-6(-6.5,-5.5)$ & $-6(-6.5,-5.4)$ & 0.991 \\
\hline
\end{tabular}

${ }^{a}$, Kruskal-Wallis test; * $\mathrm{P} \leq 0.05$ relative to the vaginal delivery group. ICD, intrapartum cesarean delivery; ECD, elective cesarean delivery; $\mathrm{IQR}$, interquartile ranges. POP, pelvic organ prolapse. 
Table 3 Prevalence of UI, SUI, UUI, and MUI; categorical variables (N, \%)

\begin{tabular}{lcccc}
\hline Groups & UI & SUI & UUI & MUI \\
\hline Vaginal delivery $(n=147)$ & $33(22.4)$ & $21(14.3)$ & $7(4.8)$ & $3(3.4)$ \\
ICD $(n=37)$ & $4(10.8)$ & $1(2.7)^{*}$ & $3(8.1)$ & $0(0)$ \\
ECD $(n=100)$ & $6(6.0)^{*}$ & $5(5.0)$ & $0(0)^{*}$ & $1(1)$ \\
$P^{a}$ & 0.001 & 0.016 & 0.037 & 0.276 \\
\hline
\end{tabular}

${ }^{\mathrm{a}}, \chi^{2}$ test; ${ }^{*} \mathrm{P}, \leq 0.05$ relative to the vaginal delivery group; ${ }^{\#}, \mathrm{P} \leq 0.05$ relative to the ICD delivery group. UI, urinary incontinenc; SUI, stress urinary incontinenc; UUI, urgent urinary incontinence; MUI, mixed urinary incontinence; ICD, intrapartum cesarean delivery; ECD, elective cesarean delivery.

Table 4 PFM strength; categorical variables (N, \%)

\begin{tabular}{|c|c|c|c|c|c|c|c|c|c|c|}
\hline Groups & \multicolumn{5}{|c|}{ Tonic PFM contraction } & \multicolumn{5}{|c|}{ Rapid PFM contraction } \\
\hline $\begin{array}{l}\text { Vaginal delivery } \\
(n=147)\end{array}$ & $3(2.0)$ & $83(56.5)$ & $47(32.0)$ & $14(9.5)$ & $0(0)$ & $0(0)$ & $61(41.5)$ & $63(42.9)$ & $23(15.6)$ & $0(0)$ \\
\hline $\operatorname{ICD}(n=37)$ & $2(5.4)$ & $9(24.3)$ & $18(48.6)$ & $8(21.6)$ & $0(0)^{*}$ & $0(0)$ & $10(27.0)$ & $18(48.6)$ & $9(24.3)$ & $0(0)$ \\
\hline $\operatorname{ECD}(n=100)$ & $1(1.0)$ & $42(42.0)$ & $44(44.0)$ & $9(9.0)$ & $4(4.0)^{\star}$ & $1(1.0)$ & $37(37.0)$ & $45(45.0)$ & $13(13.0)$ & $4(4.0)$ \\
\hline
\end{tabular}

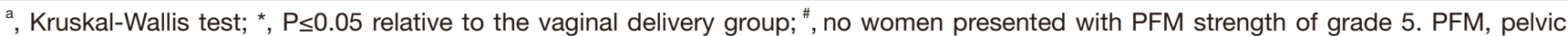
floor muscle; ICD, intrapartum cesarean delivery; ECD, elective cesarean delivery.

$(\mathrm{P} \leq 0.05)$. Our analyses also showed that during the shortterm postpartum period, the genital hiatus of women who delivered vaginally was increased in size compared to that of women who underwent ECD or ICD $(\mathrm{P} \leq 0.05)$. The Ap and $\mathrm{Bp}$ prolapse rates in the vaginal delivery group were significantly higher than those in the ECD group $(\mathrm{P} \leq 0.05)$. Points $\mathrm{C}$, pb, TVL, and D were similar among the groups $(\mathrm{P} \geq 0.05)$.

Our analysis revealed the prevalence of UI among the primiparas to be $15 \%$ (Table 3). The composition ratios of SUI, UUI, and MUI were 62.8\% (27/43), 23.3\% (10/43), and $14.0 \%(6 / 43)$, respectively. The prevalence of UI, SUI, and UUI was associated with delivery type, and major differences existed between the groups $(\mathrm{P} \leq 0.05)$. The UI prevalence in the vaginal delivery, ICD, and ECD groups was $22.4 \%(33 / 147), 10.8 \%(4 / 37)$, and $6.0 \%(6 / 100)$, respectively. In the early postpartum period, UI was less prevalent in the ECD group than in the vaginal delivery group $(\mathrm{P} \leq 0.05)$. The prevalence of SUI in the ICD group was lower than that in the vaginal delivery group $(\mathrm{P} \leq 0.05)$. Also, UUI showed a lower prevalence in the ECD group than in the ICD group at 6 to 8 weeks postpartum $(\mathrm{P} \leq 0.05)$. Notably, the prevalence of MUI was similar between the
3 groups $(\mathrm{P} \geq 0.05)$.

The tonic PFM contraction in women who underwent vaginal delivery was significantly weaker than that in the ECD and ICD groups (Table 4, $\mathrm{P} \leq 0.05$ ). No significant difference emerged between the 3 groups with respect to rapid $\mathrm{PFM}$ contraction $(\mathrm{P} \geq 0.05)$.

Some participants in this study reported lower bowel and urinary symptoms. Pelvic floor distress symptoms of women in the 3 groups are shown in Figure 2, and Table 5 shows the PFDI-20 scores. The median and IQR varied between the 3 groups. Also, the UDI- 6 and PFDI-20 scores of the ECD and vaginal delivery groups differed significantly $(\mathrm{P} \leq 0.05)$.

\section{Discussion}

Our analysis revealed significant differences in the incidence of PFD among full-term singleton primiparas based on obstetrical features. The delivery mode highly affected the cumulative incidence of PFD. ECD had a stronger association with a lower risk of POP and UI, lower PFDI20 scores, and greater PFM strength than did vaginal delivery. Also, the protective effect of ICD against PFD was 


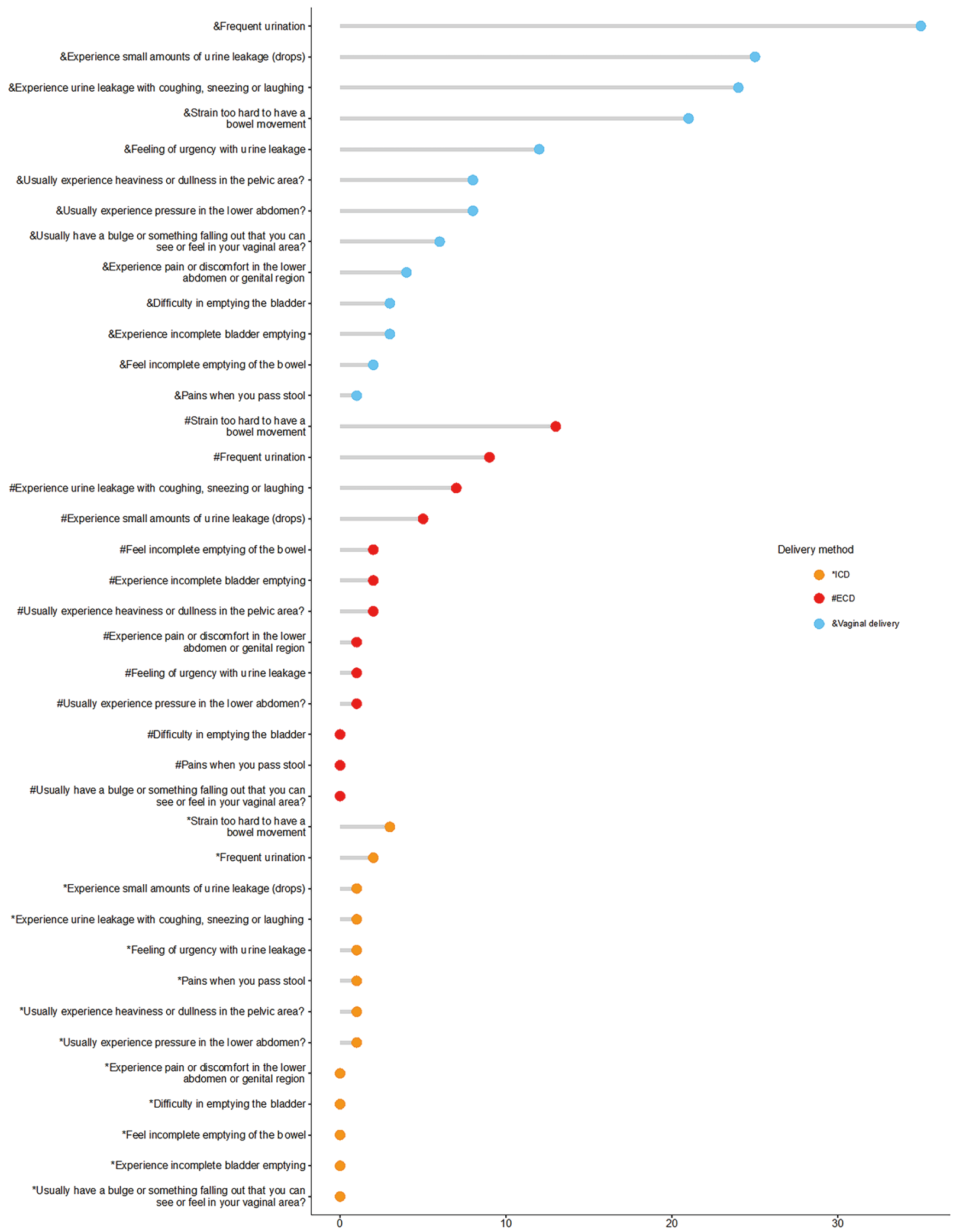

Figure 2 Pelvic floor distress symptoms. ICD, intrapartum cesarean delivery; ECD, elective cesarean delivery. 
Table 5 The 3 PFDI-20 scales; continuous variables (M, IQR)

\begin{tabular}{lcccc}
\hline Groups & PFDI-20 & POPDI-6 & CRADI-8 & UDI-6 \\
\hline Vaginal delivery $(n=147)$ & $0(0,14.5)$ & $0(0,0)$ & $0(0,0)$ & $0(0,8.25)$ \\
ICD $(n=37)$ & $0(0,6.25)$ & $0(0,0)$ & $0(0,0)$ & $0(0,0)$ \\
ECD $(n=100)$ & $0(0,0)^{\star}$ & $0(0,0)$ & $0(0,0)$ & $0(0,0)^{\star}$ \\
$P^{a}$ & 0.013 & 0.058 & 0.941 & 0.003 \\
\hline
\end{tabular}

${ }^{a}$, Kruskal-Wallis test; ${ }^{*}, \mathrm{P} \leq 0.05$ relative to the vaginal delivery group. PFM, pelvic floor muscle; PFDI-20, Pelvic Floor Distress Inventory Questionnaire-Short Form 20; ICD, intrapartum cesarean delivery; ECD, elective cesarean delivery; UDI-6, urinary distress; CRADI-8, colorectal and anal distress; POPDI-6, pelvic organ prolapse distress.

weaker than that of ECD.

Here, we evaluated POP conditions at an early point and found delivery mode to significantly influence POP-Q points Aa, Ap, gh, Ba, and Bp. We also discovered a significant correlation between vaginal delivery and prolapse of the posterior and anterior vaginal walls. A 12-year longitudinal study (11) found that POP was less commonly associated with exclusive cesarean births [odds ratio (OR), 0.11; 95\% confidence interval (CI), 0.03-0.38]. For women who delivered by cesarean section, the genital hiatus size was significantly correlated with POP. Therefore, the size of the genital hiatus can predict the occurrence of POP over time (12). This finding contradicts previous reports that in the immediate postpartum period, the delivery mode only significantly influences the measurement of POP-Q point $\mathrm{C}$ (7).

In a prospective pregnancy cohort study (13), Brown et al. found that women who underwent caesarean section in the $1^{\text {st }}$ stage of labor (adjusted OR 0.2, 95\% CI, 0.1-0.4) or before labor (adjusted OR 0.2; 95\% CI, 0.1-0.5) were more likely to develop urinary continence 3 months after birth than those who had a spontaneous vaginal birth. The adjusted OR for incontinence following caesarean delivery during the $2^{\text {nd }}$ stage of labor was 0.5 (95\% CI, 0.2-1.0). A prolonged $2^{\text {nd }}$ stage of labor was strongly correlated with an elevated risk of postpartum incontinence in women who had an operative vaginal birth (adjusted OR 1.7; 95\% CI, 1.0-2.8) or spontaneous vaginal birth (adjusted OR 1.9; 95\% CI, 1.1-3.4). Also, Viktrup et al. followed 305 primiparas and observed decreases in the prevalence of SUI as the postpartum period progressed, from $19 \%$ immediately after delivery to $6 \%$ after 3 months and to $3 \%$ after 1 year (14), suggesting that UI caused by vaginal delivery may be reversible.

Here, we observed that ECD and ICD were correlated with higher tonic PFM contraction relative to vaginal delivery. This observation suggests that vaginal delivery contributes to PFM damage in the recent postpartum period, which is consistent with findings of previous reports $(15,16)$. Notably, PFM strength was found to show a marked association with a shorter time to PFD in women who had at least 1 vaginal delivery; the same association was not observed in women who delivered by cesarean section (17). However, Afshari et al. (18) discovered no significant differences in the strength of the PFM with normal vaginal delivery compared to cesarean section. Also, Colla et al. showed that PFM contraction tended to recover spontaneously between 1 and 3 months post delivery (7).

Vaginal delivery is correlated with a higher rate of levator ani muscle (LAM) injury, enlargement of the hiatal area, increased bladder neck mobility, and puborectalis defects (19). During vaginal delivery, the levator ani expands by $2.5 \%$ to $24.5 \%$ to facilitate the widening of the levator hiatus during crowning $(20,21)$. Cases of POP have been reported to arise from injury to the levator ani muscle $(22,23)$. Stær-Jensen et al. found no increase in bladder neck mobility following cesarean delivery (24). A 2-year cross-sectional study found that the incidence of UI following cesarean section and vaginal delivery was $18.9 \%$ and $17 \%$, respectively (25), which indicated that cesarean section offered no obvious protection to the tissue of the pelvic floor. Thus, whether or not cesarean section protects against PFM damage is controversial.

The scores of the PFDI-20 questionnaire used to assess our study participants showed a relationship between the delivery mode and PFD symptoms. However, the majority of participants did not report these symptoms when filling out the questionnaire. We found that urinary distress was the most severe symptom in the women in our study. Item 7 (Do you feel the need to strain hard to have bowel movement?) had the highest CRADI-8 score, followed by item 8 (Do you feel you have not completely emptied your bowels at the end of bowel movement?). The occurrence of postpartum fecal incontinence has been reported 
previously, and it may be related to anatomical defects, such as tearing of the anal sphincter during child delivery $(26,27)$. The POPDI-6 scores were the lowest. It is possible that participants regarded the question as being too personal and thus gave a negative response, or denied having difficulty in passing stools. Clinical examination may have been able to obtain more accurate information.

To date, most studies have shown that vaginal delivery increases the risk of experiencing PFD symptoms $(28,29)$. However, our findings suggest that the damage already existed in the short term. When women are screened for pelvic floor function at 6 to 8 weeks postpartum, they should detail the specific reasons for their cesarean section. According to Ferreira et al.'s study, a significant reduction in pelvic organ descent and the hiatal area was noted over a mean of 2.7 years after a first birth (30). For long-term protection of pelvic floor function, women, especially those who deliver vaginally need to be informed of the importance of pelvic floor rehabilitation training. As well as paying attention to PFM damage and PFD in the recent postpartum period, future studies will research more effective methods to guide the restoration of pelvic floor function, with the aim of improving the quality of life of women affected by PFD.

Currently, there is evidence that pregnancy is a contributing factor to PFD. Studies have shown that close follow-up and high adherence to PFM strength-training protocols after delivery and during pregnancy can treat or prevent UI (31). Thus, PFM exercises are recommended for pregnant women, as they can improve PFM function during the postpartum period (grade of recommendation: A) (32).

This study had multiple strengths. First, both subjective symptoms and objective data were used to assess PFD. A more comprehensive observation may give a more accurate picture and allow our results to be generalized to the entire population. Second, the study was carried out at a tertiary hospital, which allowed us to avoid selection bias and to recruit a multiregional population, thereby increasing the generalizability of our findings. Third, attention was paid to transitions between delivery modes, with $13.0 \%$ (37/284) of the participants undergoing cesarean delivery after labor commenced.

However, the present study is also limited, because we did not include data of the long-term effects of delivery on pelvic floor function. Also, the prospective design with the inclusion of data related to PFM function before and during pregnancy. Finally, the collection of data based on European and American women would improve the generalizability of our results.

\section{Conclusions}

In conclusion, compared to vaginal delivery, ECD was strongly linked to a lower risk of POP and UI, lower PFDI20 scores, and stronger tonic PFM strength. Furthermore, the protective effect of ICD against PFD is weaker than that of ECD.

\section{Acknowledgments}

We thank the participants, students, and nurses for their contribution to this study.

Funding: This work was supported by a grant from the Wenzhou Municipal Science and Technology Bureau (Y20180286).

\section{Footnote}

Reporting Checklist: The authors have completed the STROBE reporting checklist. Available at http://dx.doi. org/10.21037/apm-21-485

Data Sharing Statement: Available at http://dx.doi. org/10.21037/apm-21-485

Conflicts of Interest: All authors have completed the ICMJE uniform disclosure form (available at http://dx.doi. org/10.21037/apm-21-485). The authors have no conflicts of interest to declare.

Ethical Statement: The authors are accountable for all aspects of the work in ensuring that questions related to the accuracy or integrity of any part of the work are appropriately investigated and resolved. All procedures performed in this study involving human participants were in accordance with the Declaration of Helsinki (as revised in 2013). Ethical approval for this study was granted by the institutional review board of the Second Affiliated Hospital of Wenzhou Medical University (Zhejiang, China) (No. LCKY2019-287). Written informed consent was obtained from all participants.

Open Access Statement: This is an Open Access article distributed in accordance with the Creative Commons Attribution-NonCommercial-NoDerivs 4.0 International License (CC BY-NC-ND 4.0), which permits the noncommercial replication and distribution of the article with 
the strict proviso that no changes or edits are made and the original work is properly cited (including links to both the formal publication through the relevant DOI and the license). See: https://creativecommons.org/licenses/by-nc-nd/4.0/.

\section{References}

1. Bo K, Frawley HC, Haylen BT, et al. An International Urogynecological Association (IUGA)/International Continence Society (ICS) joint report on the terminology for the conservative and nonpharmacological management of female pelvic floor dysfunction. Neurourol Urodyn 2017;36:221-44.

2. Nygaard I, Barber MD, Burgio KL, et al. Prevalence of symptomatic pelvic floor disorders in US women. JAMA 2008;300:1311-6.

3. Wu JM, Matthews CA, Conover MM, et al. Lifetime risk of stress urinary incontinence or pelvic organ prolapse surgery. Obstet Gynecol 2014;123:1201-6.

4. Mant J, Painter R, Vessey M. Epidemiology of genital prolapse: observations from the Oxford Family Planning Association Study. Br J Obstet Gynaecol 1997;104:579-85.

5. Dolan LM, Hilton P. Obstetric risk factors and pelvic floor dysfunction 20 years after first delivery. Int Urogynecol J 2010;21:535-44.

6. Torrisi G, Minini G, Bernasconi F, et al. A prospective study of pelvic floor dysfunctions related to delivery. Eur J Obstet Gynecol Reprod Biol 2012;160:110-5.

7. Colla C, Paiva LL, Ferla L, et al. Pelvic floor dysfunction in the immediate puerperium, and 1 and 3 months after vaginal or cesarean delivery. Int J Gynaecol Obstet 2018;143:94-100.

8. Tennfjord MK, Hilde G, Stær-Jensen J, et al. Dyspareunia and pelvic floor muscle function before and during pregnancy and after childbirth. Int Urogynecol J 2014;25:1227-35.

9. Chen X, Gong Y, Wu D, et al. Pre- and postoperative evaluation of pelvic floor muscle function in POP patients using surface electromyography and digital palpation. Neurourol Urodyn 2014;33:403-7.

10. Zhao Y, Zou L, Xiao M, et al. Effect of different delivery modes on the short-term strength of the pelvic floor muscle in Chinese primipara. BMC Pregnancy Childbirth 2018;18:275.

11. Glazener C, Elders A, MacArthur C, et al. Childbirth and prolapse: long-term associations with the symptoms and objective measurement of pelvic organ prolapse. BJOG 2013;120:161-8.
12. Blomquist JL, Muñoz A, Carroll M, et al. Association of Delivery Mode With Pelvic Floor Disorders After Childbirth. JAMA 2018;320:2438-47.

13. Brown SJ, Gartland D, Donath S, et al. Effects of prolonged second stage, method of birth, timing of caesarean section and other obstetric risk factors on postnatal urinary incontinence: an Australian nulliparous cohort study. BJOG 2011;118:991-1000.

14. Viktrup L, Lose G, Rolff M, et al. The symptom of stress incontinence caused by pregnancy or delivery in primiparas. Obstet Gynecol 1992;79:945-9.

15. Memon H, Handa VL. Pelvic floor disorders following vaginal or cesarean delivery. Curr Opin Obstet Gynecol 2012;24:349-54.

16. Lavy Y, Sand PK, Kaniel CI, et al. Can pelvic floor injury secondary to delivery be prevented? Int Urogynecol J 2012;23:165-73.

17. Blomquist JL, Carroll M, Muñoz A, et al. Pelvic floor muscle strength and the incidence of pelvic floor disorders after vaginal and cesarean delivery. Am J Obstet Gynecol 2020;222:62.e1-62.e8.

18. Afshari P, Dabagh F, Iravani M, et al. Comparison of pelvic floor muscle strength in nulliparous women and those with normal vaginal delivery and cesarean section. Int Urogynecol J 2017;28:1171-5.

19. de Araujo CC, Coelho SA, Stahlschmidt P, et al. Does vaginal delivery cause more damage to the pelvic floor than cesarean section as determined by $3 \mathrm{D}$ ultrasound evaluation? A systematic review. Int Urogynecol J 2018;29:639-45.

20. Dixit P, Shek KL, Dietz HP. How common is pelvic floor muscle atrophy after vaginal childbirth? Ultrasound Obstet Gynecol 2014;43:83-8.

21. Shek KL, Dietz HP. Intrapartum risk factors for levator trauma. BJOG 2010;117:1485-92.

22. DeLancey JO, Morgan DM, Fenner DE, et al. Comparison of levator ani muscle defects and function in women with and without pelvic organ prolapse. Obstet Gynecol 2007;109:295-302.

23. Dietz HP, Simpson JM. Levator trauma is associated with pelvic organ prolapse. BJOG 2008;115:979-84.

24. Stær-Jensen J, Siafarikas F, Hilde G, et al. Postpartum recovery of levator hiatus and bladder neck mobility in relation to pregnancy. Obstet Gynecol 2015;125:531-9.

25. Barbosa AM, Marini G, Piculo F, Rudge CV, Calderon IM, Rudge MV. Prevalence of urinary incontinence and pelvic floor muscle dysfunction in primiparae two years after cesarean section: cross-sectional study. Sao Paulo Med J 
2013;131:95-9.

26. Fenner DE, Genberg B, Brahma P, et al. Fecal and urinary incontinence after vaginal delivery with anal sphincter disruption in an obstetrics unit in the United States. Am J Obstet Gynecol 2003;189:1543-9; discussion 1549-50.

27. Wheeler TL, 2nd, Richter HE. Delivery method, anal sphincter tears and fecal incontinence: new information on a persistent problem. Curr Opin Obstet Gynecol 2007;19:474-9.

28. Gyhagen M, Bullarbo M, Nielsen TF, et al. The prevalence of urinary incontinence 20 years after childbirth: a national cohort study in singleton primiparae after vaginal or caesarean delivery. BJOG 2013;120:144-51.

29. Volloyhaug I, Morkved S, Salvesen O, et al. Pelvic organ prolapse and incontinence 15-23 years after first delivery: a cross-sectional study. BJOG 2015;122:964-71.

Cite this article as: Zhang $\mathrm{X}$, Zhang $\mathrm{X}$, Wang $\mathrm{Y}$, Huang $\mathrm{X}$, Chen X, Wang L. Short-term effects of delivery methods on postpartum pelvic floor function in primiparas: a retrospective study. Ann Palliat Med 2021;10(3):3386-3395. doi: 10.21037/ apm-21-485
30. Ferreira CWS, Atan IK, Martin A, et al. Pelvic organ support several years after a first birth. Int Urogynecol J 2017;28:1499-505.

31. Morkved S, Bo K. Effect of pelvic floor muscle training during pregnancy and after childbirth on prevention and treatment of urinary incontinence: a systematic review. $\mathrm{Br}$ J Sports Med 2014;48:299-310.

32. Abrams P, Andersson KE, Apostolidis A, et al. 6th International Consultation on Incontinence. Recommendations of the International Scientific Committee: EVALUATION AND TREATMENT OF URINARY INCONTINENCE, PELVIC ORGAN PROLAPSE AND FAECAL INCONTINENCE. Neurourol Urodyn 2018;37:2271-2.

(English Language Editor: J. Reynolds) 